\title{
Post-Stroke Sexual Disorders and Its Real-Life Experience within Couples in Brazzaville
}

\author{
Josué Euberma Diatewa1,2*, Prince Eliot Galiéni Sounga Banzouzi2,3, Ghislain Armel Mpandzou',2, \\ Dinah Happhia Boubayi Motoula Latou 1,2, Gabrielle-Gracia Ontsira1, Karen L. Obondzo Aloba1, \\ Anani Wanscels Sévérin Odzebe ${ }^{2,4}$, Paul Macaire Ossou-Nguiet ${ }^{1,2}$
}

\author{
${ }^{1}$ Department of Neurology, University Hospital of Brazzaville, Brazzaville, Congo \\ ${ }^{2}$ Faculty of Health Sciences, University Marien Ngouabi, Brazzaville, Congo \\ ${ }^{3}$ Department of Neurology, General Hospital of Loandjili, Pointe Noire, Congo \\ ${ }^{4}$ Department of Urology, University Hospital of Brazzaville, Brazzaville, Congo \\ Email: *lejd01@gmail.com
}

How to cite this paper: Diatewa, J.E. Banzouzi, P.E.G.S., Mpandzou, G.A., Latou, D.H.B.M., Ontsira, G.-G., Aloba, K.L.O., Odzebe, A.W.S. and Ossou-Nguiet, P.M. (2021) Post-Stroke Sexual Disorders and Its Real-Life Experience within Couples in Brazzaville. World Journal of Neuroscience, $11,22-33$

https://doi.org/ 10.4236/wins.2021.111004

Received: January 2, 2021

Accepted: February 22, 2021

Published: February 25, 2021

Copyright $\odot 2021$ by author(s) and Scientific Research Publishing Inc. This work is licensed under the Creative Commons Attribution International License (CC BY 4.0).

http://creativecommons.org/licenses/by/4.0/

\begin{abstract}
Background: Post-stroke sequelae can have repercussions on the sexual life and relational life of patients and their partners. Objectives: To determine the frequencies of sexual disorders after a first stroke event; to identify the factors associated with sexual disorders; to explore the real-life experience of sexual disorders within couples. Methods: It was an analytical cross-sectional study, conducted on patients followed up for a first stroke and their partners. It was carried out at public and private hospitals in Brazzaville, Congo, during the period of patient follow-up, from May to September 2019 (5 months). The Female Sexual Function Index, International Index of Erectile Function 5 and interviews were used to describe sexual aspects. The real-life experience of couples was explored using standardized and pre-established questionnaires. Results: Of the 36 patients who had taken up again sexual intercourse after stroke, 29 (80.6\%) were men. Among the post-stroke sexual disorders, erectile dysfunction (53.2\%) and ejaculatory dysfunction (40.4\%) were the most frequent in men. Decrease of sexual desire was predominant in women $(100 \%)$. Factors associated with erectile dysfunction were sleep disorder $(\mathrm{p}=$ $0.007)$ and mean sleep duration per night $(\mathrm{p}=0.01)$. Lack of verbal and non-verbal communication of sexual problems and psychological effects was noted in $77.8 \%$ of patients and $60 \%$ of their partners. The most frequent psychological effects were: in patients, frustration (52.8\%), attitude of person decreased (50\%) and sadness (41.7\%); in partners, attitude of carer (86.7\%). Conclusion: Post-stroke sexual disorders are frequent in our context. Sleep disorders and mean sleep duration per night, psychological factors seem to have a negative impact on the sexual life and relational life of stroke patients and their partners. It is important to improve the sex management of couples.
\end{abstract}




\section{Keywords}

Post-Stroke, Sexual Disorders, Brazzaville

\section{Introduction}

Strokes remain a public health problem throughout the world because of high mortality and sequel [1] [2] [3].

The management of stroke survivors aims to improve their quality of life. This improvement involves a prior assessment of residual disability that is either motor, cognitive or phasic [2] [3] [4] [5]. Among the disabilities, there are sexual disorders which affect $50 \%$ to $80 \%$ of stroke survivors [6].

Studies on the sexual aspects and relational factors in stroke survivors and their partners have been carried out in many countries [6] [7] [8] [9] [10]. In Congo, research into post-stroke sexual disorders has focused on erectile dysfunction [11]. In this study, erectile dysfunction after stroke was common (51.92\%) with an impact on the lives of the couple.

Therefore, it seemed important to us to make a survey of all the sexual dysfunctions in patients after a first stroke event. The aim of this study is to improve the sex management of stroke survivors. Our objectives were to determine the frequencies of post-stroke sexual disorders, to identify the associated factors to sexual disorders and to explore the real-life experience of sexual disorders within couples.

\section{Methods}

This was an analytical cross-sectional study, approved by the Ethics Committee of Congo (number: 182; date: April 22, 2019) and conducted according to the Declaration of Helsinki. It carried out at public and private hospitals in Brazzaville, Congo, from May to September 2019 (5 months). It focused on stroke survivors with sexual disorders came back at follow-up visit and their partners. Patients and their declared partners have been exhaustively identified.

For stroke survivors, the inclusion criteria were: to be the victim of a first stroke event at least of six months and confirmed by brain imaging; to give informed consent to participate in the study; to be over 18 years old; to be unscathed from sexual disorders before the onset of stroke; to be devoid of phasic, major cognitive and chronic psychiatric pathologies.

For partners, the inclusion criteria were: to live with a wife or husband suffering from a stroke; to give informed consent to participate in the study.

The Female Sexual Function Index (FSFI) and International Index of Erectile Function 5 (IIEF-5) [12], as well as interviews, were used to describe the sexual aspects in stroke survivors. FSFI and IIEF-5 scores were determined according to the methods described in the documents related to these tests [12]. The exploration of the real-life experience of sexual disorders within couples was carried out 
using standardized and pre-established questionnaires.

The data collected were analyzed using the statistics software CSPro version 7.2. Qualitative variables were expressed in the form of frequency and percentage. For quantitative variables, mean and standard deviation were determined. The Pearson and Fisher chi-squared tests were used for comparison of qualitative variables. Comparison of quantitative variables was performed using the Student's t-test. Significance level was set at $\mathrm{p}<0.05$.

\section{Results}

Of the 103 stroke survivors came back at follow-up visit, 85 (82.5\%) agreed to participate in the present study.

Among the 85 stroke survivors, 65 (76.5\%) were included in the study. The characteristics of the population included in the study are regrouped together in Table 1. The mean age of stroke survivors was $52.9 \pm 10$ years, with limits of 20 and 73 years. The mean time of stroke onset was $14.1 \pm 10.5$ months, with limits of 6 and 48 months.

Of the 65 stroke survivors, $39(60 \%)$ had sexual activities. There are 32 (82.1\%) men and 7 (17.9\%) women. Among the 39 stroke survivors, 36 (92.3\%) had sexual disorders. These occurred within the first six months after stroke in $30(84.6 \%)$ patients and beyond in $6(15.4 \%)$ patients.

Of the 36 stroke survivors with sexual disorders, 15 (41.7\%) had a sleep disorder; this was an interrupted sleep. Twenty-two (61.1\%) patients were afraid of stroke recurrence that may occur during or after sexual intercourses. Among the 36 stroke survivors, there were 7 (19.4\%) women and 29 (80.6\%) men.

Table 1. Characteristics of the population included in the study.

\begin{tabular}{cccc}
\hline & & $\mathbf{n}$ & $\%$ \\
\hline Gender & Men & 47 & 72.3 \\
Type of stroke & Women & 18 & 27.3 \\
\hline \multirow{2}{*}{$\begin{array}{c}\text { Arterial territories of } \\
\text { arterial infarctions }\end{array}$} & Arterial infarction & 43 & 66.2 \\
& Intracerebral hemorrhage & 22 & 33.8 \\
\hline Topography of & Middle cerebral artery & 36 & 83.7 \\
intracerebral hemorrhages & Posterior cerebral artery & 4 & 9.3 \\
\hline & Anterior cerebral artery & 3 & 7 \\
Rype of neurological sequelae & Deep & 19 & 86.4 \\
\hline Neurological sequelae & Lobar & 3 & 13.6 \\
\hline & Yes & 47 & 72.3
\end{tabular}


The 7 female stroke survivors had a score of FSFI less than 26.5, indicating the existence of sexual functioning disorder. Their score of the domain related to sexual desire was equal to or less than 5 , indicating the decrease of sexual desire. The other sexual functions, namely sexual awakening, vaginal lubrication, orgasm and sexual satisfaction, could not be identified.

The 29 male stroke survivors had the following sexual disorders: decreased sexual desire $(\mathrm{n}=11 ; 38 \%)$, erectile dysfunction $(\mathrm{n}=21 ; 72.4 \%)$, ejaculation disorders $(\mathrm{n}=19 ; 65.5 \%)$ and anorgasmia $(\mathrm{n}=3 ; 10.3 \%)$. Ejaculation was premature in $79 \%$ of cases and delayed in $21 \%$ of cases. Erectile dysfunction was mild in $57 \%$ of cases and moderate in $43 \%$ of cases. In contrast, the following sexual disorders were noted in 15 male stroke survivors who had not yet taken up again sexual intercourses: decreased sexual desire $(n=4 ; 26.7 \%)$; erectile dysfunction $(\mathrm{n}=4 ; 26.7 \%)$.

Erectile dysfunction was the only sexual disorder significantly associated with the following factors: sleep disorder $(\mathrm{p}=0.007)$ and mean duration of sleep per night $(\mathrm{p}=0.01)$ (Tables 2-4).

Among the 36 stroke survivors who had taken up again sexual intercourses, 28 (77.8\%) did not communicate verbally or non-verbally with their partners about sexual problems and psychological effects following upon post-stroke sexual

Table 2. Assessment of factors associated with decreased sexual desire.

\begin{tabular}{|c|c|c|c|c|c|c|}
\hline & & \multicolumn{5}{|c|}{ Decreased sexual desire } \\
\hline & & \multicolumn{2}{|c|}{ Yes } & \multicolumn{2}{|c|}{ No } & \multirow{2}{*}{ p-value } \\
\hline & & $\mathrm{n}$ & $\%$ & $\mathrm{n}$ & $\%$ & \\
\hline \multirow[b]{2}{*}{ Sensitive sequela } & Yes & 1 & 5 & 2 & 6.3 & \multirow[b]{2}{*}{0.8} \\
\hline & No & 19 & 95 & 30 & 93.8 & \\
\hline \multirow{2}{*}{ Type of stroke } & Arterial infarction & 12 & 60 & 19 & 59.4 & \multirow{2}{*}{0.9} \\
\hline & Intracerebral hemorrhage & 8 & 40 & 13 & 40.6 & \\
\hline \multirow{3}{*}{$\begin{array}{l}\text { Arterial territories of } \\
\text { arterial infarctions }\end{array}$} & Middle cerebral artery & 10 & 83.3 & 15 & 78.9 & \multirow{3}{*}{0.2} \\
\hline & Posterior cerebral artery & 2 & 16.7 & 1 & 5.3 & \\
\hline & Anterior cerebral artery & 0 & 0 & 3 & 15.8 & \\
\hline \multirow{2}{*}{$\begin{array}{l}\text { Topography of } \\
\text { intracerebral hemorrhages }\end{array}$} & Lobar & 0 & 0 & 3 & 23.1 & \multirow{2}{*}{0.1} \\
\hline & Deep & 8 & 100 & 10 & 76.9 & \\
\hline \multirow{2}{*}{ Sleep disorder } & Yes & 7 & 15 & 12 & 37.5 & \multirow{2}{*}{0.8} \\
\hline & No & 13 & 85 & 20 & 62.5 & \\
\hline \multirow{2}{*}{$\begin{array}{c}\text { Mean sleep } \\
\text { duration per night }\end{array}$} & $<8$ hours & 8 & 40 & 10 & 31.2 & \multirow{2}{*}{0.5} \\
\hline & $\geq 8$ hours & 12 & 60 & 22 & 68.8 & \\
\hline \multirow{2}{*}{ Decreased self-esteem } & Yes & 5 & 25 & 9 & 28.1 & \multirow{2}{*}{0.8} \\
\hline & No & 15 & 75 & 23 & 71.9 & \\
\hline \multirow{2}{*}{ Anxiety } & Yes & 1 & 5 & 7 & 21.9 & \multirow{2}{*}{0.1} \\
\hline & No & 19 & 95 & 25 & 78.1 & \\
\hline
\end{tabular}


Table 3. Assessment of factors associated with erectile dysfunction.

\begin{tabular}{|c|c|c|c|c|c|c|}
\hline & & \multicolumn{5}{|c|}{ Erectile dysfunction } \\
\hline & & \multicolumn{2}{|c|}{ Yes } & \multicolumn{2}{|c|}{ No } & \multirow{2}{*}{$\mathrm{p}$-value } \\
\hline & & $\mathrm{n}$ & $\%$ & $\mathrm{n}$ & $\%$ & \\
\hline \multirow{2}{*}{ Sensitive sequela } & Yes & 2 & 8 & 0 & 0 & \multirow{2}{*}{0.21} \\
\hline & No & 23 & 92 & 30 & 100 & \\
\hline \multirow{2}{*}{ Type of stroke } & Arterial infarction & 13 & 52 & 8 & 61.5 & \multirow{2}{*}{0.71} \\
\hline & Intracerebral hemorrhage & 12 & 48 & 5 & 38.5 & \\
\hline \multirow{3}{*}{$\begin{array}{l}\text { Arterial territories } \\
\text { of arterial infarctions }\end{array}$} & Middle cerebral artery & 11 & 84.6 & 6 & 75 & \multirow{3}{*}{0.1} \\
\hline & Posterior cerebral artery & 2 & 15.4 & 0 & 0 & \\
\hline & Anterior cerebral artery & 0 & 0 & 2 & 25 & \\
\hline \multirow{2}{*}{$\begin{array}{l}\text { Topography of } \\
\text { intracerebral hemorrhages }\end{array}$} & Lobar & 0 & 0 & 3 & 23.1 & \multirow{2}{*}{0.2} \\
\hline & Deep & 8 & 100 & 10 & 76.9 & \\
\hline \multirow{2}{*}{ Sleep disorder } & Yes & 13 & 52 & 1 & 7.7 & \multirow{2}{*}{0.007} \\
\hline & No & 12 & 48 & 12 & 92.3 & \\
\hline \multirow{2}{*}{$\begin{array}{c}\text { Mean sleep } \\
\text { duration per night }\end{array}$} & $<8$ hours & 12 & 48 & 1 & 7.7 & \multirow{2}{*}{0.01} \\
\hline & $\geq 8$ hours & 13 & 52 & 12 & 92.3 & \\
\hline \multirow{2}{*}{ Decreased self-esteem } & Yes & 7 & 28 & 2 & 15.4 & \multirow{2}{*}{0.38} \\
\hline & No & 18 & 72 & 11 & 84.6 & \\
\hline \multirow{2}{*}{ Anxiety } & Yes & 4 & 16 & 2 & 15.4 & \multirow{2}{*}{0.96} \\
\hline & No & 21 & 84 & 11 & 84.6 & \\
\hline
\end{tabular}

Table 4. Assessment of factors associated with ejaculatory dysfunction.

\begin{tabular}{|c|c|c|c|c|c|c|}
\hline & & \multicolumn{5}{|c|}{ Ejaculatory dysfunction } \\
\hline & & \multicolumn{2}{|c|}{ Yes } & \multicolumn{2}{|c|}{ No } & \multirow{2}{*}{$\mathrm{p}$-value } \\
\hline & & $\mathrm{n}$ & $\%$ & $\mathrm{n}$ & $\%$ & \\
\hline \multirow{2}{*}{ Sensitive sequela } & Yes & 2 & 10.5 & 0 & 0 & \multirow{2}{*}{0.29} \\
\hline & No & 11 & 88.5 & 10 & 100 & \\
\hline \multirow{2}{*}{ Type of stroke } & Arterial infarction & 11 & 57.9 & 9 & 64.3 & \multirow{2}{*}{0.57} \\
\hline & Intracerebral hemorrhage & 8 & 42.1 & 5 & 35.7 & \\
\hline \multirow{3}{*}{$\begin{array}{l}\text { Arterial territories } \\
\text { of arterial infarctions }\end{array}$} & Middle cerebral artery & 10 & 90.9 & 7 & 77.8 & \multirow{3}{*}{0.1} \\
\hline & Posterior cerebral artery & 1 & 9.1 & 0 & 0 & \\
\hline & Anterior cerebral artery & 0 & 0.0 & 2 & 22.2 & \\
\hline \multirow{2}{*}{$\begin{array}{l}\text { Topography of } \\
\text { intracerebral hemorrhages }\end{array}$} & Lobar & 0 & 0 & 1 & 20 & \multirow{2}{*}{0.1} \\
\hline & Deep & 8 & 100 & 4 & 80 & \\
\hline \multirow{2}{*}{ Sleep disorder } & Yes & 8 & 42.1 & 3 & 21.4 & \multirow{2}{*}{0.21} \\
\hline & No & 11 & 57.9 & 11 & 78.6 & \\
\hline \multirow{2}{*}{$\begin{array}{l}\text { Mean sleep duration } \\
\text { per night }\end{array}$} & $<8$ hours & 9 & 47.4 & 4 & 28.6 & \multirow{2}{*}{0.27} \\
\hline & $\geq 8$ hours & 10 & 52.6 & 10 & 71.4 & \\
\hline \multirow{2}{*}{ Decreased self-esteem } & Yes & 5 & 26.3 & 3 & 21.4 & \multirow{2}{*}{0.38} \\
\hline & No & 14 & 73.7 & 11 & 78.6 & \\
\hline \multirow{2}{*}{ Anxiety } & Yes & 4 & 21.1 & 2 & 14.3 & \multirow{2}{*}{0.61} \\
\hline & No & 15 & 78.9 & 12 & 85.7 & \\
\hline
\end{tabular}


disorders. They experienced the sexual problems and psychological effects in silence. The real-life experience of sexual disorders and psychological effects in silence was noted in $9(60 \%)$ partners out of a total number of 15 partners. The mean age of the partners was $48.8 \pm 11.3$ years, with limits of 29 and 72 years.

The explanations, provided by the 28 stroke survivors and 9 partners to justify the real-life experience of sexual problems and psychological effects in silence, were: "inconvenience" in 15 (53.6\%) stroke survivors; "how to tackle the question?" in 13 (46.4\%) stroke survivors and 7 (77.8\%) partners. The solutions envisaged to resolve the health status were: self-medication in $5(17.9 \%)$ stroke survivors; need for help from a physician in $3(10.7 \%)$ stroke survivors, family member in $3(10.7 \%)$ stroke survivors and friend in $6(21.4 \%)$ stroke survivors. Two (22.2\%) partners had accepted the health status of their sick wives or husbands. The 28 stroke survivors had hoped to meet a specialist of sexual health at the time of follow-up visit.

The psychological effects felt by the 36 stroke survivors with sexual disorders were: optimism $(\mathrm{n}=28 ; 77.8 \%)$, frustration $(\mathrm{n}=19 ; 52.8 \%)$, attitude of person decreased $(n=18 ; 50 \%)$, sadness $(n=15 ; 41.7 \%)$, anxiety $(n=12 ; 33.3 \%)$, nervousness $(\mathrm{n}=11 ; 30.6 \%)$, decreased self-esteem $(\mathrm{n}=11 ; 30.6 \%)$ and fatality $(\mathrm{n}=$ 5 ; 13.9\%). In partners, it was noted: optimism $(\mathrm{n}=15 ; 100 \%)$, attitude of carer $(\mathrm{n}=13 ; 86.7 \%)$, nervousness $(\mathrm{n}=5 ; 33.3 \%)$ and attitude of sexual partner $(\mathrm{n}=2$; $13.3 \%)$.

\section{Discussion}

This study is about the epidemiology of post-stroke sexual disorders, factors associated with these disorders and real-life experience of these disorders within couples.

The predominance of male stroke survivors observed in our series $(80.6 \%)$ has also been found in other studies [10] [13]-[18].

Our stroke survivors have a young age. This epidemiological feature has also been reported by other authors [5] [15] [19].

The rate of our patients who have taken up again sexual intercourses after the onset of first stroke event $(60 \%)$ gets closer to those estimated by other investigators $(67 \%$ - 68\%) [15] [20]. The absence of taking up again sexual intercourse, noted in the $40 \%$ of our patients, may mainly be due to the fear of stroke recurrence, diminished sexual desire, attitude of care-giver, hesitation of partner, loss of habit to having sex, side effects of medication, physical aversion felt by the partner towards his stroke wife or husband, diminished or absent sensitivity of paralyzed body side, loss of verbal and non-verbal communication, fear of failure of sexual intercourse [5] [8] [21]-[26].

Studies report that aged women can carry on having satisfactory sexual intercourse and sexuality is an integral part of their lives [27] [28] [29]. In addition, researchers had validated, in women over 65 years old, the IFSF which is a pertinent tool for global assessment of female sexual functioning [14] [28]. Howev- 
er, some elderly women can have a minimal sexual dysfunction before the onset of stroke. This dysfunction would only be a factor of decompensation or increase [29] [30]. In our study, the sexual disorders, presented by the 7 female stroke survivors of whom the mean age is 50 years, would probably be due to the stroke. The elevated rate of decrease of sexual desire, noted in our female stroke survivors (100\%), has also been observed in other series [10] [15] [31] [32].

It has been noted, according to studies carried out in male stroke survivors, an elevated proportion of decreased sexual desire, ejaculation disorders and erectile dysfunction [8] [16] [32]. This is also encountered in our study. The disparity in the frequencies of different post-stroke sexual disorders may be due to the following factors: location of brain lesion; severity of motor deficit; degree of dependence for acts of everyday life; moment of sexual disorder outcome in the course of medical patient examination because sexual problems can be temporary, continue or get worse over time; involvement of hypertension, diabetes mellitus, medication and psychosocial factors [5] [33] [34] [35] [36] [37].

The frequency of our male stroke survivors with orgasm disorders is lower (10.3\%) than those reported by other investigators (range: 40\% - 55\%) [15] [38].

Literature reports that the frequency of stroke survivors with decreased sexual desire varies from $26 \%$ to $79 \%$ [13] [23] [31] [33]. The overall frequency of our stroke survivors with decreased sexual desire (50\%) falls in with this interval.

In the present study, and among ejaculation disorders, it is noted a higher rate of patients with premature ejaculation (79\% of cases) compared with that of patients with delayed ejaculation (21\%). Our data agree with those reported in other series [11] [31] [39]. Researchers have found a rate of stroke survivors with decreased ejaculation that is higher than that of stroke survivors with absent ejaculation [40]. This does not corroborate our data.

Literature data reveal that 20 to $78 \%$ of stroke survivors have an erectile dysfunction [33] [37]. The overall frequency of our stroke survivors with erectile dysfunction (56.8\%) belongs to this interval. The disparity in the degrees of erectile dysfunction has been observed according to studies. In our series, erectile dysfunction is milder ( $57 \%$ of cases) than moderate ( $43 \%$ of cases). This characteristic has also been observed in other studies [11] [18] [23] [31]. Investigators have reported a higher rate of stroke survivors with diminished erectile function compared with that of patients with absent erectile function [15] [16] [40] [41]. This is not in line with the findings of our study. Multifactorial causes would be at the origin of the differences observed in the degrees of erectile dysfunction.

Erectile dysfunction is the only sexual disorder significantly correlated with 2 factors: sleep disorder $(\mathrm{p}=0.007)$ and mean duration of sleep per night $(\mathrm{p}=$ 0.01 ). Our data support the findings of other investigators who have reported that erectile dysfunction is correlated with obstructive sleep apnea syndrome [42] [43] [44].

The link between anxiety and post-stroke sexual disorders has been established in some studies [36]. In our series, no correlation is noted. The differences 
observed in the results would be due among other things to the size of the samples.

Anxiety and other side effects following upon post-stroke sexual disorders experienced by the stroke survivors, as well as partner's attitude, can lead to the decrease or absence of verbal and non-verbal communication within couples [6] [23] [24] [40]. In our study, more than half of couples do not communicate verbally and non-verbally. Literature reports that sexuality after stroke is wrapped up in silence; this manifests itself at the individual level by a difficulty of communication [6] [7]. Our patients' need to being out of the silence is expressed oneself by seeking help from a physician (10.7\%), family member (10.7\%) and friend $(21.4 \%)$ and by hoping to meet a sexual counselor at the time of follow-up visit $(77.8 \%)$. The solutions to being out of the silence, similar to those of our patients, have also been reported by other investigators [45]. The practice of self-medication noted in our patients (17.9\%) expresses the need to being out of the health status, of course, but it is probably only a consolation over the discomfort of the real-life experience of silence. This practice has also been reported by other authors [26].

The side effects following upon post-stroke sexual disorders, experienced by our patients and their partners, are mainly psychological effects. This is similar to the findings of other investigators [7] [9] [24] [36].

\section{Strengths and Limitations}

Our research in different centers and the exhaustive sampling made it possible to identify patients suffering from a first stroke and to present sexual disorders in all outpatient neurology consultations in Brazzaville. This allows us to extend the results obtained to the urban population of the city.

The use of different quiz to assess sexual disorders and experience is one approach encouraged for surveys of this kind [27]. These tests have been validated and used in most randomized trials [27] [28]. Trudel et al. [28] reported a very strong internal consistency (Cronbach's alpha) of IFSF, which was estimated to be 0.91 .

The high participation rate $(76.5 \%)$ reflected the desire of patients to come out of the shadows and find solutions to this problem; sexuality being an important element of the quality of life. The low participation rate of the partners (52.3\%) therefore did not seem to have had any effect on this desire for a solution. Likewise, in various surveys on sexuality, the participation rate is often low. Chambon [5] in France reported a participation rate of $40 \%$. Humphrey [21] in a much older study reported a much lower participation rate of $17 \%$. This explains some of the difficulties encountered in our study such as obtaining the cooperation of certain partners, sexuality being a taboo and private subject. Likewise, our low recruitment can be explained by the fact that 6 months after a stroke, some patients are lost to follow-up and no longer want to return to the follow-up consultation. 


\section{Conclusion}

Post-stroke sexual disorders are frequent in Brazzaville. Next to sleep disorder and mean sleep duration per night, psychological effects seem to be factors which have repercussions on the sexual life and relational life of stroke patients and their partners. It is important to implement sexual counseling in departments of neurology in order to improve the quality of life of couples.

\section{Conflicts of Interest}

The authors declare no conflicts of interest regarding the publication of this paper.

\section{References}

[1] Béjot, Y., Touzé, E., Jacquin, A., Giroud, M. and Mas, J.-L. (2009) Épidémiologie des accidents vasculaires cérébraux. Medical Sciences, 25, 727-732. https://doi.org/10.1051/medsci/2009258-9727

[2] Ossou-Nguiet, P.M., Mouanga, A.M., Youmbert, A.N., Mpandzou, G.A., Bandzouzi, P.E.S., Latou, D.H.M., et al. (2017) Dépression post Accident Vasculaire Cérébral au CHU de Brazzaville. Revue Neurologique, 173, S171-S172. https://doi.org/10.1016/j.neurol.2017.01.330

[3] Ossou-Nguiet, P.M., Gnonlonfoun, D., Bandzouzi-Ndamba, B., Mouanga, A.M., Assogba, K. and Matali, E. (2012) Qualité de vie des aphasiques post-AVC à Brazzaville. Revue Neurologique, 168, A141. https://doi.org/10.1016/j.neurol.2012.01.363

[4] Charfi, N., Trabelsi, S., Turki, M., Mâalej Bouali, M., Zouari, L., Dammak, M., et al. (2017) Impact du handicap physique et des troubles émotionnels concomitants sur la qualité de vie en post-AVC. L'Encéphale, 43, 429-434. https://doi.org/10.1016/j.encep.2016.05.014

[5] Chambon, X. (2010) Analyse de la sexualité chez la personne hémiplégique. Pratique et Formation en Médecine Physique et Réadaptation. Journal de Réadaptation Médicale, 30, 12-17. https://doi.org/10.1016/j.jrm.2010.01.002

[6] McGrath, M., Lever, S., McCluskey, A. and Power, E. (2019) How Is Sexuality after Stroke Experienced by Stroke Survivors and Partners of Stroke Survivors? A Systematic Review of Qualitative Studies. Clinical Rehabilitation, 33, 293-303. https://doi.org/10.1177/0269215518793483

[7] Thompson, H.S. and Ryan, A. (2009) The Impact of Stroke Consequences on Spousal Relationships from the Perspective of the Person with Stroke. Journal of Clinical Nursing, 18, 1803-1811. https://doi.org/10.1111/j.1365-2702.2008.02694.x

[8] Calabrò, R.S., Giuseppe Gervasi, G. and Bramanti, P. (2011) Male Sexual Disorders Following Stroke: An Overview. International Journal of Neuroscience, 121, 598-604. https://doi.org/10.3109/00207454.2011.600647

[9] Kitzmüller, G. and Ervik, B. (2015) Female Spouses' Perceptions of the Sexual Relationship with Stroke-Affected Partners. Sexuality and Disability, 33, 499-512. https://doi.org/10.1007/s11195-015-9404-x

[10] Grenier Genest, A. and Courtois, F. (2017) Les accidents vasculaires cérébraux et leur impact sur la sexualité. Sexologies, 26, 115-135.

https://doi.org/10.1016/j.sexol.2016.11.001

[11] Ossou-Nguiet, P.M., Odzébé, A.S.W., Bandzouzi-Ndamba, B., Banzouzi, L.F., Gnonlonfoun, D., Bouya, P.A., et al. (2012) Dysfonction érectile après un accident 
vasculaire cérébral à Brazzaville. Revue Neurologique, 168, 538-542. https://doi.org/10.1016/j.neurol.2012.04.001

[12] Giuliano, F. (2013) Les questionnaires recommandés en médecine sexuelle. Progrès en Urologie, 23, 811-821. https://doi.org/10.1016/j.purol.2013.01.006

[13] Kimura, M., Murata, Y., Shimoda, K. and Robinson, R. (2001) Sexual Dysfunction Following Stroke. Comprehensive Psychiatry, 42, 217-222. https://doi.org/10.1053/comp.2001.23141

[14] Kissela, B.M., Khoury, J.C., Alwell, K., Moomaw, C.J., Woo, D., Adeoye, O., et al. (2012) Age at Stroke: Temporal Trends in Stroke Incidence in a Large, Biracial Population. Neurology, 79, 1781-1787. https://doi.org/10.1212/WNL.0b013e318270401d

[15] Akinpelu, A.O., Osose, A.A., Odole, A.C. and Odunaiya, N.A. (2013) Sexual Dysfunction in Nigerian Stroke Survivors. African Health Sciences, 13, 639-645.

https://doi.org/10.4314/ahs.v13i3.17

[16] Dusenbury, W., Palm Johansen, P., Mosack, V. and Steinke, E.E. (2017) Determinants of Sexual Function and Dysfunction in Men and Women with Stroke: A Systematic Review. International Journal of Clinical Practice, 71, 129-169. https://doi.org/10.1111/ijcp.12969

[17] Diatewa, J.E., Kombate, D., Dongmo, J.-J., Apetse, K., Assogba, K. and Balogou, A.A.K. (2018) A Prognostic Challenge of Brainstem Stroke for the Countries of Sub-Saharan Africa: Case of Togo. Clinical Neurology and Neuroscience, 2, 61-67. https://doi.org/10.33425/2641-4333.1014

[18] Eko Purwata, T., Andaka, D., Nuartha, A., Wiratni, C. and Ketut Sumada, K. (2019) Positive Correlation between Left Hemisphere Lesion and Erectile Dysfunction in Post-Stroke Patients. Macedonian Journal of Medical Sciences, 7, 363-368. https://doi.org/10.3889/oamjms.2019.125

[19] Yoon, J.G., Zarayeneh, N. and Suh, S.C. (2017) Interrelationship between the General Characteristics of Korean Stroke Patients and the Variables of the Sexual Functions: Random Forest and Boosting Algorithm. The Journal of Physical Therapy Science, 29, 613-617. https://doi.org/10.1589/jpts.29.613

[20] Sjögren, K. and Fugl-Meyer, A.R. (1982) Adjustment to Life after Stroke with Special Reference to Sexual Intercourse and Leisure. Journal of Psychosomatic Research, 26, 409-417. https://doi.org/10.1016/0022-3999(82)90015-0

[21] Humphrey, M. and Kinsella, G. (1980) Sexuality and Disability. Journal of the Royal Society of Medicine, 3, 150-153. https://doi.org/10.1007/BF01100746

[22] Buffum, J. (1982) Pharmacosexology: The Effects of Drugs on Sexual Function, a Review. Journal of Psychoactive Drugs, 14, 5-44. https://doi.org/10.1080/02791072.1982.10471907

[23] Korpelainen, J.T., Nieminen, P. and Myllylä, V.V. (1999) Sexual Functioning among Stroke Patients and Their Spouses. Stroke, 30, 715-719. https://doi.org/10.1161/01.STR.30.4.715

[24] Soulier, B. (2001) Un amour comme tant d'autres? Handicaps moteurs et sexualité. Association des Paralysés de France (APF), Paris.

[25] Fekih-Romdhane, F., Elkissi, Y. and Nacef, F. (2015) Évaluation de la fonction sexuelle dans un groupe d'hommes bipolaires de type 1 en période de rémission. Sexologies, 24, 93-100. https://doi.org/10.1016/j.sexol.2014.07.011

[26] Jung, J.-H., Kam, S.-C., Choi, S.-M., Jae, S.-U., Lee, S.-H. and Hyun, J.-S. (2008) Sexual Dysfunction in Male Stroke Patients: Correlation between Brain Lesions and 
Sexual Function. Urology, 71, 99-103. https://doi.org/10.1016/j.urology.2007.08.045

[27] Lindau, S.T., Schumm, O., Laumann, E.O., Levinson, W., O’Muircheartaigh, C.A. and Waite, L.J. (2007) A Study of Sexuality and Health among Older Adults in the United States. The New England Journal of Medicine, 257, 762-774.

https://doi.org/10.1056/NEJMoa067423

[28] Trudel, G., Dargis, L., Cadieux, J., Villeneuve, L., Préville, M. and Boyer, R. (2012) Validation de l'Index de la fonction sexuelle féminine (IFSF) et présentation de normes chez les femmes aînées. Sexologies, 21, 161-167. https://doi.org/10.1016/j.sexol.2012.01.003

[29] Sharpe, T.H. (2004) Introduction to Sexuality in Later Life. The Family Journal, 12, 199-205. https://doi.org/10.1177/0022167804264106

[30] Mimoun, S. (2003) Ménopause, andropause et fonction sexuelle. Gynecologie, Obstetrique \& Fertilite, 31, 141-146.

[31] Monga, T.N., Lawson, J.S. and Inglis, J. (1986) Sexual Dysfunction in Stroke Patients. Archives of Physical Medicine and Rehabilitation, 67, 19-22.

[32] Boldrini, P., Basaglia, N. and Calanca, M.C. (1991) Sexual Changes in Hemiparetic Patients. Archives of Physical Medicine and Rehabilitation, 72, 202-207.

[33] Bianchi-Demicheli, F., Sekoranja, L., Temperli, P., Lövblad, K.O., Ortigue, S. and Sztajzel, R. (2007) Fonction sexuelle masculine après accident vasculaire cérébral. Revue Médicale Suisse, 3, 32152.

[34] Lue, T.F. (2000) Erectile Dysfunction. The New England Journal of Medicine, 342, 1802-1813. https://doi.org/10.1056/NEJM200006153422407

[35] Phe, V. and Roupret, M. (2012) Erectile Dysfunction and Diabetes: A Review of the Current Evidence-Based Medicine and a Synthesis of the Main Available Therapies. Diabetes \& Metabolism, 38, 1-13. https://doi.org/10.1016/j.diabet.2011.09.003

[36] Bugnicourt, J.-M., Hamy, O., Canaple, S., Lamy, C. and Legrand, C. (2014) Impaired Sexual Activity in Young Ischaemic Stroke Patients: An Observational Study. European Journal of Neurology, 21, 140-146. https://doi.org/10.1111/ene.12277

[37] Dai, H., Wang, J., Zhao, Q., Ma, J., Gong, X., Wang, L., Bao, B., Li, H. and Wang, B. (2020) Erectile Dysfunction and Associated Risk Factors in Male Patients with Ischemic Stroke. A Cross-Sectional Study. Medicine, 99, e18583. https://doi.org/10.1097/MD.0000000000018583

[38] Cheung, R.T.F. (2002) Sexual Functioning in Chinese Stroke Patients with Mild or No Disability. Cerebrovascular Diseases, 14, 122-128.

https://doi.org/10.1159/000064739

[39] Azanmasso, H., Alagnidé, E., Hounmenou, J.G., Niama Natta, D. and Kpadonou, T.G. (2016) Sexual Disorders in Stroke Patients Compared with Control Subjects in Benin: A Prospective Study. Annals of Physical and Rehabilitation Medicine, 59, e69-e70. https://doi.org/10.1016/j.rehab.2016.07.161

[40] Tamama, Y., Tamamb, L., Akila, E., Yasanc, A. and Tamamd, B. (2008) Post-Stroke Sexual Functioning in First Stroke Patients. European Journal of Neurology, 15, 660-666. https://doi.org/10.1111/j.1468-1331.2008.02184.x

[41] Bener, A., Al-Hamaq, A.O.A.A., Kamran, S. and Al-Ansari, A. (2008) Prevalence of Erectile Dysfunction in Male Stroke Patients, and Associated Co-Morbidities and Risk Factors. International Urology and Nephrology, 40, 701-708. https://doi.org/10.1007/s11255-008-9334-y

[42] Gonçalves, M.A., Guilleminault, C., Ramos, E., Palha, A. and Paiva, T. (2005) Erectile Dysfunction, Obstructive Sleep Apnea Syndrome and Nasal CPAP Treatment. 
Sleep Medicine, 6, 333-339. https://doi.org/10.1016/j.sleep.2005.03.001

[43] Teloken, P.E., Smith, E.B., Lodowsky, C., Freedom, T. and Mulhall, J.P. (2006) Defining Association between Sleep Apnea Syndrome and Erectile Dysfunction. Urology, 67, 1033-1037. https://doi.org/10.1016/j.urology.2005.11.040

[44] Reishtein, J.L., Maislin, G. and Weaver, T.E. (2010) Outcome of CPAP Treatment on Intimate and Sexual Relationships in Men with Obstructive Sleep Apnea. Journal of Clinical Sleep Medicine, 6, 221-226. https://doi.org/10.5664/jcsm.27817

[45] Nilsson, M.I., Fugl-Meyer, K., von Koch, L. and Ytterberg, C. (2017) Experiences of Sexuality Six Years after Stroke: A Qualitative Study. The Journal of Sexual Medicine, 14, 797-803. https://doi.org/10.1016/j.jsxm.2017.04.061

\section{Abbreviations}

FSFI: Female Sexual Function Index

IIEF-5: International Index of Erectile Function 5

AI: Arterial Infarction

ICH: Intracerebral Hemorrhage 